\title{
Left coronary artery from the pulmonary artery Physiological considerations of surgical correction
}

\author{
JANE SOMERVILLE and DONALD N. ROSS \\ Institute of Cardiology and National Heart Hospital, London
}

A 13-year-old boy with anomalous origin of the left coronary artery from the pulmonary artery has been studied before and after anastomosis of the artery to the aorta, using a saphenous vein graft. There was suggestive evidence of improved left ventricular function following operation. The presence of associated mitral regurgitation is suspected from the auscultatory findings.

When the left coronary artery arises from the pulmonary artery, serious ischaemia of the left ventricle may cause death in infancy, but if intercoronary anastomotic channels are adequate, survival to middle age or even older is possible (Kaunitz, 1947). In these circumstances, the blood flow through the left coronary artery is reversed, resulting in a small left-to-right shunt into the pulmonary artery. In those who survive infancy, the left ventricle is abnormal and unexpected cardiac arrest can occur at any age.

The following case illustrates the possibility of restoring the normal anatomy.

\section{CASE REPORT}

P.W., a boy aged 13, was referred to the National Heart Hospital in 1967 with the diagnosis of suspected persistent duct. He was the third child and product of a normal pregnancy. The birth weight was $6 \mathrm{lb}$. $4 \mathrm{oz} .(2 \cdot 8 \mathrm{~kg}$.) and he thrived normally during infancy. A heart murmur was heard at 13 months during admission to hospital for gastroenteritis, and a chest radiograph at that time was said to show cardiomegaly. From the age of 4 years a continuous murmur was heard at the left sternal edge. He continued to develop normally, but apart from being breathless on running compared with other boys, he was without symptoms. He had no angina of effort.

Examination showed a tall, thin boy with normal peripheral pulses and a blood pressure of 125/70 $\mathrm{mm}$. Hg. The left ventricle was enlarged and slightly overactive. At rest the second sound was split normally (Fig. 1) but reversed after mild effort. A loud third sound was present at rest. A soft continuous murmur which increased on expiration was heard in the pulmonary area when he was first examined as an out-patient and a pansystolic

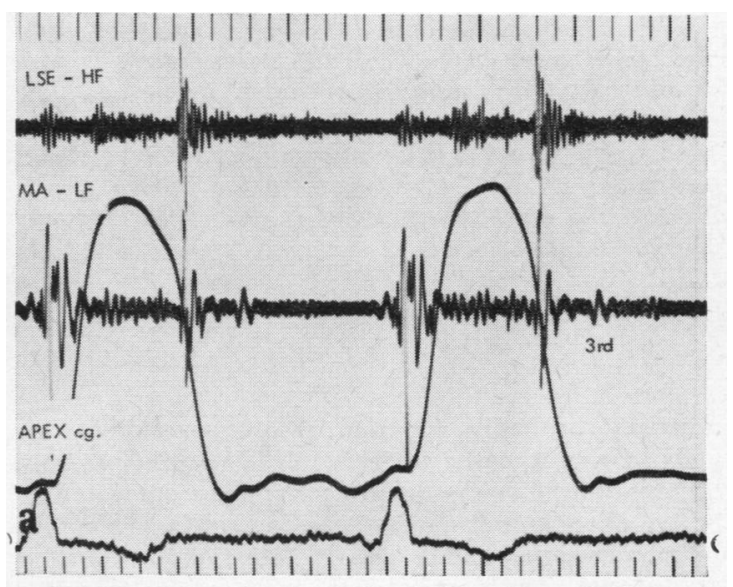

(a)

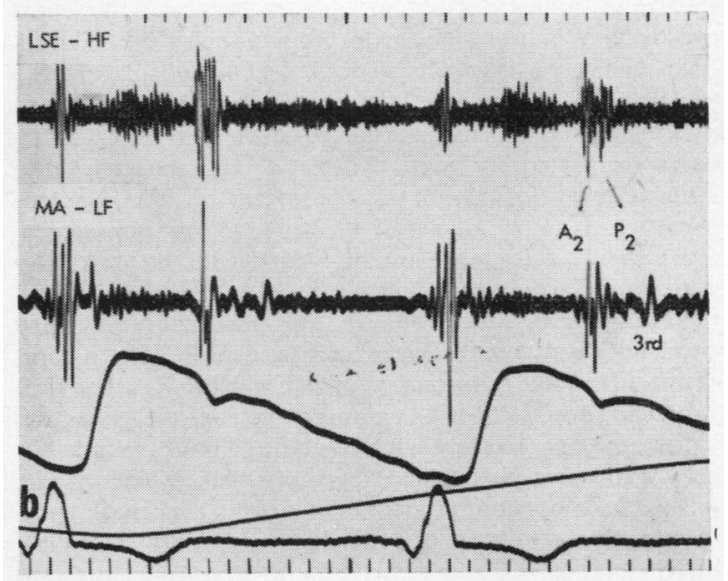

(b)

Legend to Fig. 1 (a) and (b) on page 208. 


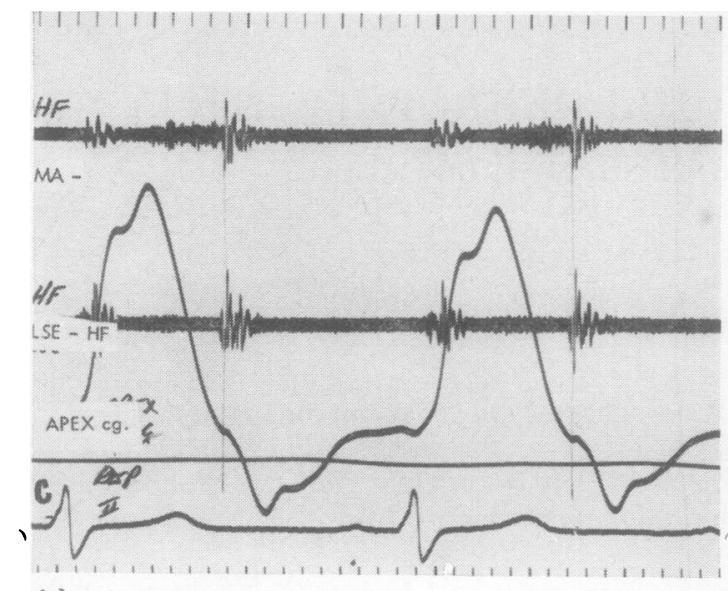

(c)

FIG. 1. Phonocardiograms (a) before operation with apex cardiogram (Apex Cg.), (b) before operation with carotid pulse (Car.), (c) after operation. Before operation there is a loud third sound and apical pansystolic murmur. The second sound is split normally and a continuous murmur is present. After operation the third sound is lessened; no continuous murmur is seen. A late systolic murmur is still obvious at the apex and lower L.S.E. L.S.E. = left sternal edge; M.A. = apex; H.F. $=$ high frequency; $L . F .=$ low frequency.

murmur, probably separate, was apparent at the apex. Lying quietly in bed in the ward, no continuous murmur was detected, but there appeared to be an ejection murmur starting in mid-systole in the pulmonary area and a clearly late systolic murmur at the apex. The physical signs in the ward suggested possible obstructive cardiomyopathy, but in view of the signs in the out-patient department and the chest radiograph, a coronary artery fistula was considered. The chest radiograph showed cardiomegaly which had been worse at age $2 \frac{1}{2}$ years, and slight pulmonary plethora (Fig. 2). Left axis deviation and left ventricular hypertrophy with wide $Q$ waves suggesting anterolateral infarction was present on the electrocardiogram (Fig. 3). Serial electrocardiograms suggested a gradual increase in left ventricular hypertrophy with age. Cardiac catheterization when he was aged 13 years showed elevation of the resting pulmonary capillary wedge pressure and a small left-to-right shunt into the pulmonary artery (Table 1). The left ventricle could not be entered retrogradely as the catheter kept passing down a huge right coronary artery into which contrast medium was injected (Fig. 4). A left coronary artery entering the main pulmonary artery was opacified retrogradely from an injection into the right coronary artery. A pulmonary arteriogram did not show the abnormal left coronary artery. In view of the possible dangers of bacterial endocarditis and the apparent abnormality of the left ventricle, surgical correction was advised.

On 11 August 1967 exploration through a median sternotomy revealed a large tortuous right coronary $\frac{\omega}{7}$ artery arising from the root of the aorta, and a large $\mathbb{\Phi}$ but less thick and tortuous left coronary artery originating from the left sinus of the main pulmonary trunk. The left cononary artery was dissected at its $\overrightarrow{0}$ origin from the main pulmonary artery and clamped $\overrightarrow{-}$ for 20 minutes. This did not affect ventricular action $\vec{\omega}$ or the electrocardiogram. A length of saphenous vein was then dissected from the right groin and ana- $\vec{x}$ stomosed to the front of the aorta, brought over in the pulmonary artery and anastomosed distally to iv the divided left coronary artery. A good flow and i pulse was achieved in the graft.

There was a pale area, $5 \times 6 \mathrm{~cm}$., at the apex and $ᄋ$ laterally which was thinned out at its centre and easily dimpled by the finger. It looked like an $\vec{z}$ ischaemic fibrous area of infarction in the myocardium.

The boy made an uninterrupted recovery from the operation and returned to school three weeks later. Recatheterization one year later showed normal. pressures and no left-to-right shunt (Table I).

\section{T A B L E 1}

RESULTS OF CARDIAC CATHETERIZATION BEFORE AND AFTER OPERATION

\begin{tabular}{l|c|c|c|c}
\hline \multirow{2}{*}{} & \multicolumn{4}{|c|}{ Pressure (mm. Hg) } \\
\cline { 2 - 4 } & $\begin{array}{c}\text { Mean } \\
\text { P.C. }\end{array}$ & P.A. & R.V. & Syst. \\
\hline $\begin{array}{c}\text { Before } \\
\text { Year } \\
\text { after }\end{array}$ & 16 & $30 / 15$ & $33 / 0$ & $125 / 75$ \\
\hline & 9 & $20 / 12$ & $21 / 0$ & $120 / 80$ \\
\hline
\end{tabular}

\begin{tabular}{l|c|c|c|c|c}
\hline & \multicolumn{5}{|c|}{ Oxygen Saturation (\%) } \\
\cline { 2 - 6 } & P.A. & R.V. & R.A. & S.V.C. & Syst. \\
\hline $\begin{array}{l}\text { Before } \\
\text { 1 Year } \\
\text { after }\end{array}$ & $66-74$ & 62 & 64 & 64 & 96 \\
\hline
\end{tabular}

P.C. = pulmonary capillary wedge; $\mathbf{P . A} .=$ pulmonary artery; R.V. = right ventricle; Syst. = systemic artery

R.A. = right atrium; S.V.C. $=$ superior vena cava

Aortography confirmed that the graft was patent $\tilde{O}$ for the first $2 \mathrm{~cm}$., but it was uncertain if the left $\underset{\omega}{N}$ coronary artery was completely perfused from the 0 aorta owing to faulty radiological technique. The

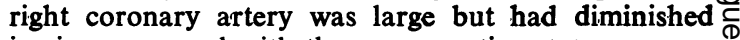
in size compared with the pre-operative state.

Exercise tests showed an improved tolerance following operation (Table II). There was loss of a third sound at rest and the second split normally $\underset{\mathbb{D}}{\mathbb{D}}$ after rest and after effort (Fig. 1c). There was no $\bigcirc$ alteration in the electrocardiogram. The patient still $\mathbb{Q}$ had a late systolic murmur at the left sternal edge and apex at rest. 


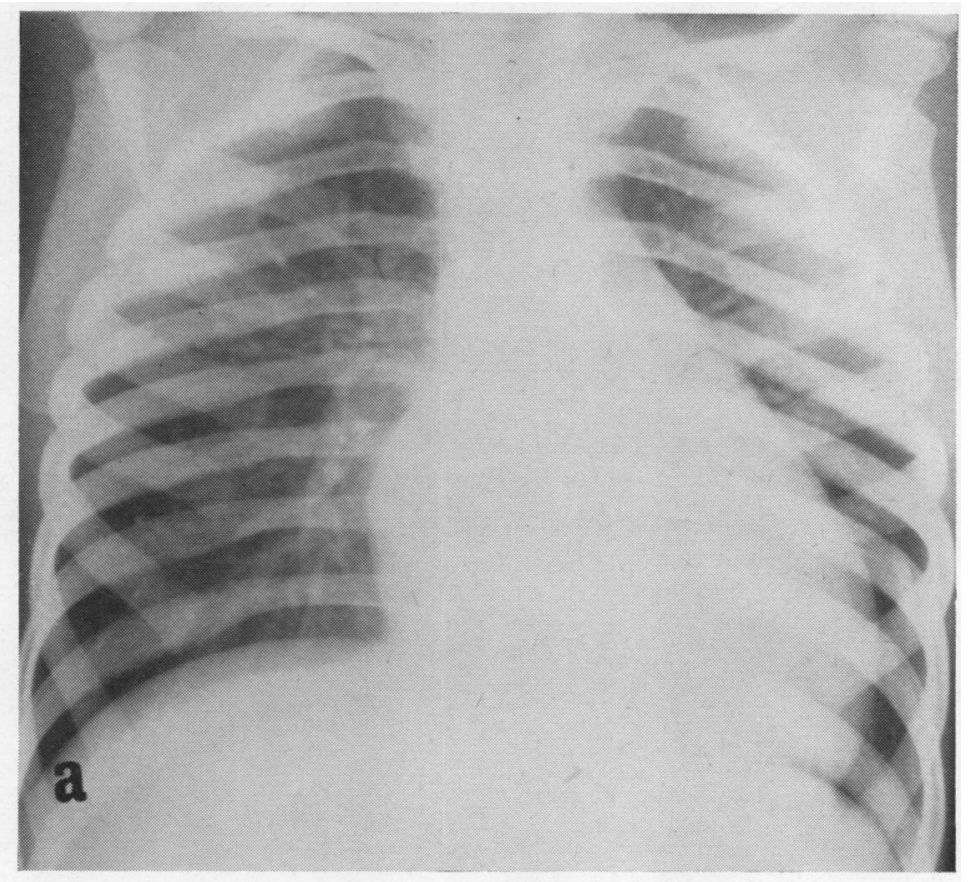

(a)

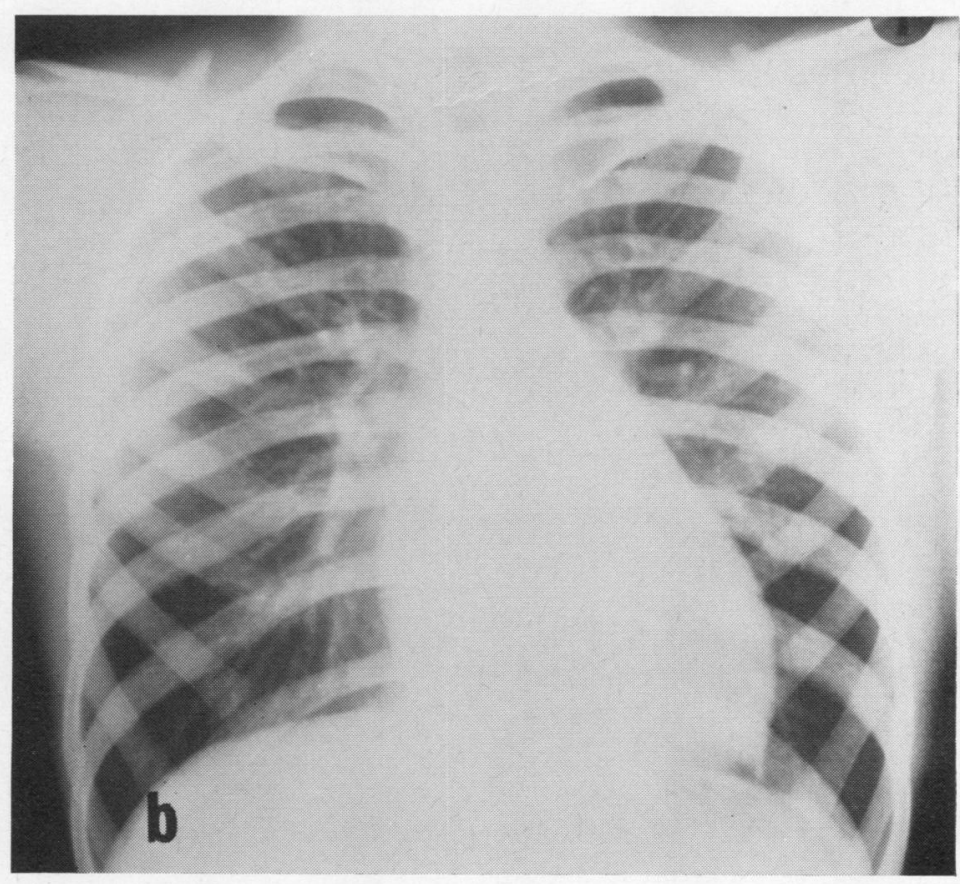

(b)

FIG. 2. Chest radiographs (a) age $2 \frac{1}{2}$ years, (b) age 13 years. The cardiomegaly and left atrial enlargement were greater at age $2 \frac{1}{2}$ years. Slight pulmonary plethora is obvious at age 13 years. 

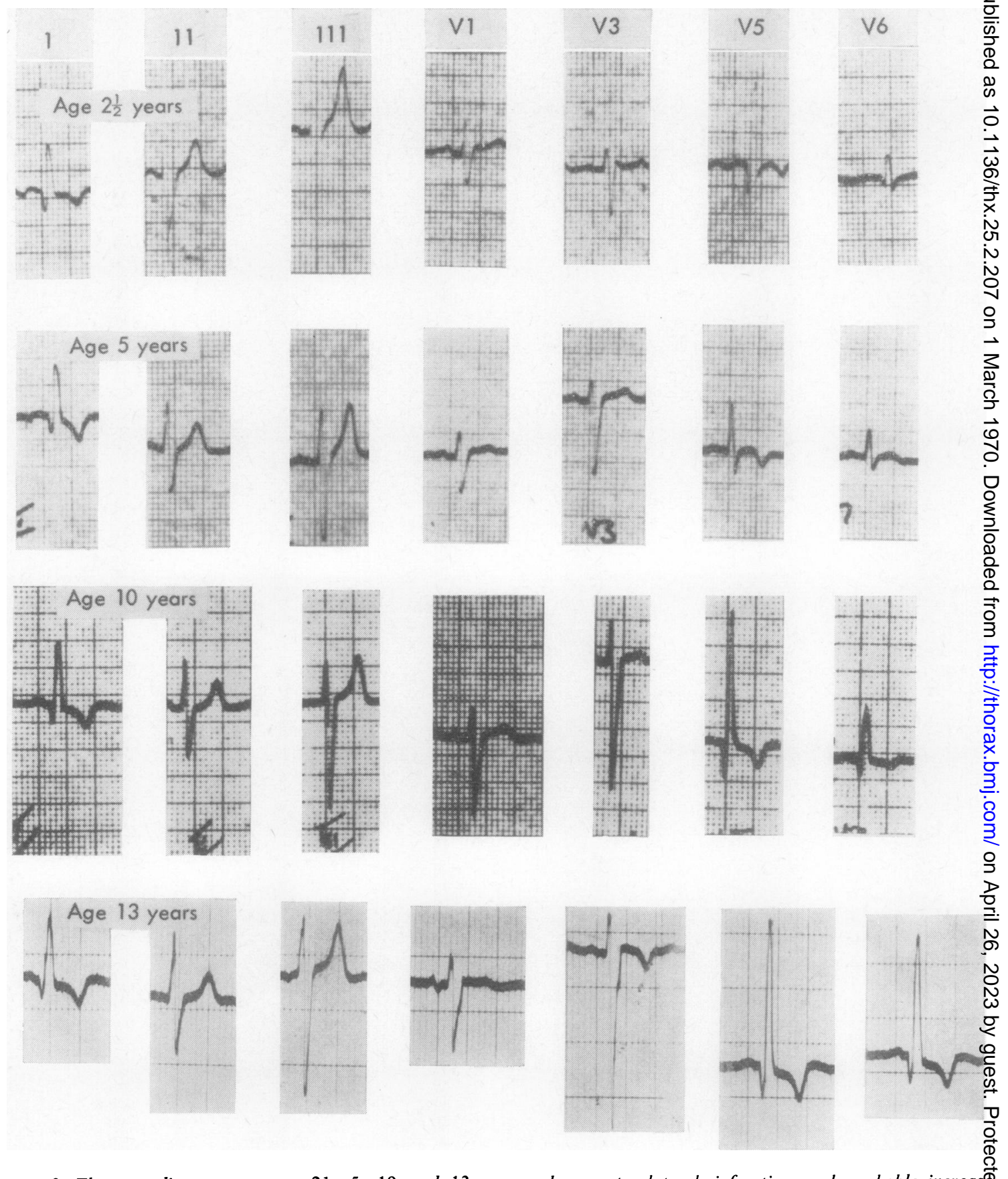

FIG. 3. Electrocardiograms at age 21, 5, 10 and 13 years show anterolateral infarction and probable increas $\frac{1}{2}$ in left ventricular hypertrophy. 


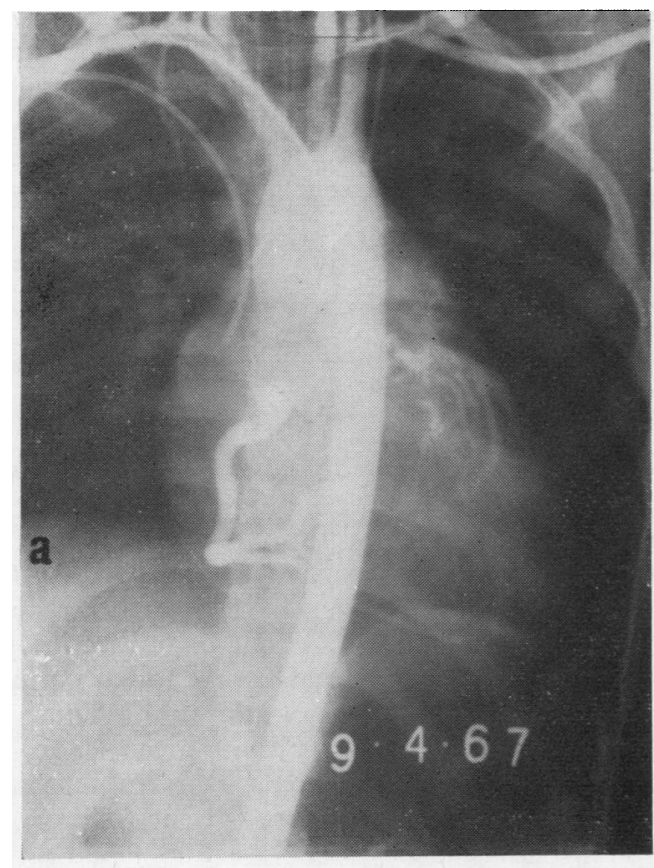

(a)

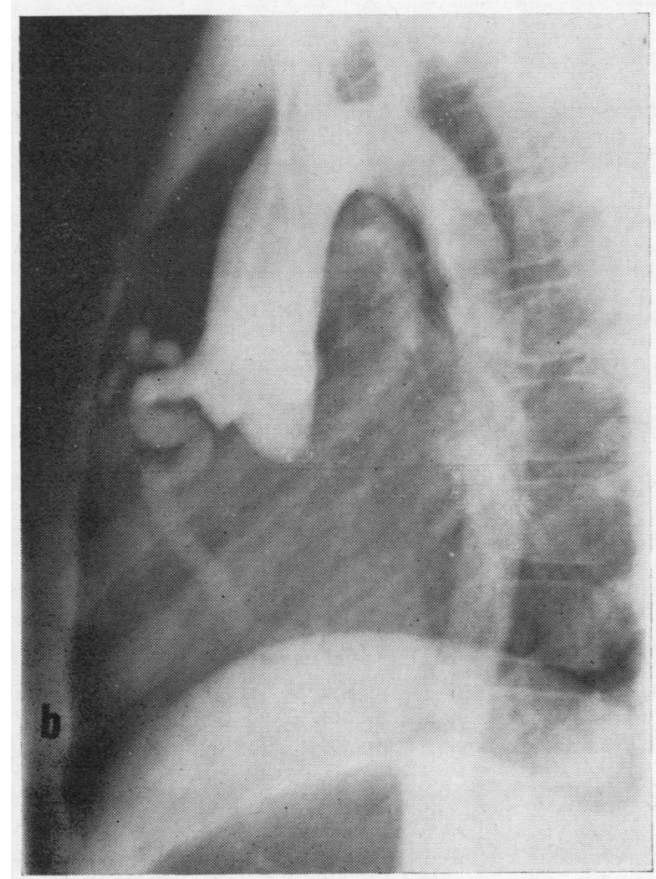

(b)

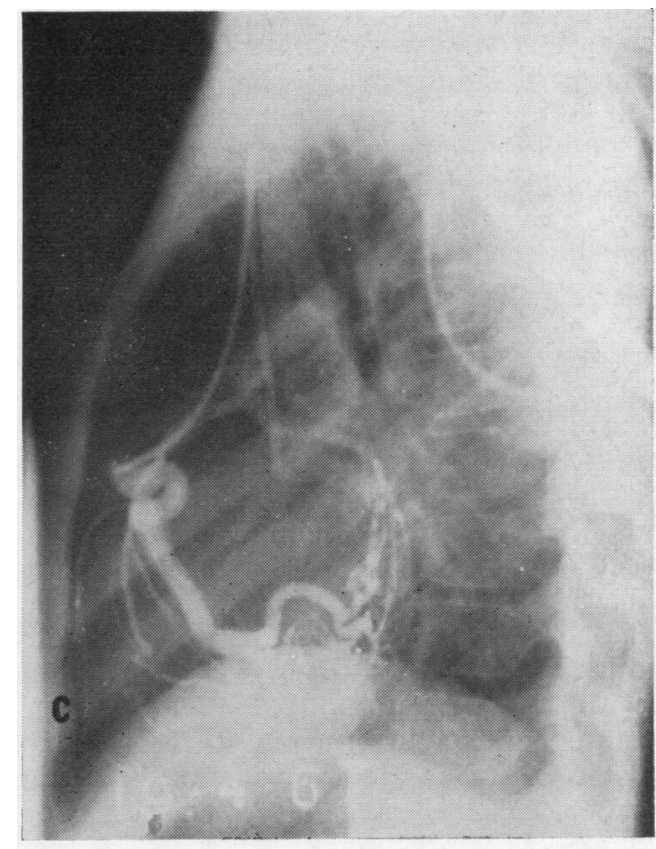

(c)

FIG. 4. Large right coronary artery filled with retrograde filling of the left coronary artery (a) anteroposterior view from aortogram, (b) lateral view from aortogram showing large conal branch, (c) lateral view from right coronary injection showing complete retrograde opacification of the left coronary artery including circumflex branch.

T A B L E I I

COMPARISON OF HEART RATES BEFORE AND AFTER SURGERY AT DIFFERENT WORK LOADS ON BICYCLE ERGOMETER

\begin{tabular}{|c|c|c|c|c|c|c|}
\hline & \multirow{2}{*}{$\underset{\text { Rest }}{\text { At }}$} & \multicolumn{5}{|c|}{ After 2 minutes at: } \\
\hline & & $\begin{array}{r}100 \\
\text { kpm. }\end{array}$ & $\begin{array}{r}300 \\
\text { kpm. }\end{array}$ & $\begin{array}{r}500 \\
\mathbf{k p m} .\end{array}$ & $\begin{array}{r}600 \\
\text { kpm. }\end{array}$ & $\begin{array}{r}700 \\
\mathrm{kpm} .\end{array}$ \\
\hline \multirow{2}{*}{$\begin{array}{l}\text { Before } \\
1 \text { Year } \\
\text { after }\end{array}$} & 86 & 96 & 122 & 157 & - & - \\
\hline & 74 & 90 & 110 & 136 & 148 & 155 \\
\hline
\end{tabular}

\section{DISCUSSION}

Although survival to the seventh decade is recorded with anomalous origin of the left coronary artery, sudden death may occur in the second or third decades, and premature angina is common in those who survive infancy (George and Knowlan, 1959). The main problem with this condition is in the infant with left ventricular failure, but because of high surgical mortality 
Nora, MacNamara, Hillman, Sommerville, and Cooley (1968) have recommended medical management in infancy with definitive surgery later. Even if the patient is asymptomatic, as many are in childhood and adolescence, there must be something to be gained by improving the condition of the left ventricle. Suggestive evidence of an abnormally functioning left ventricle in the present case was the loud third sound, reversed split on effort and elevated resting wedge pressure. It is likely that the effort dyspnoea was also related to this.

Successful ligation of the left coronary artery close to its origin has been described in infants and older children (Case, Morrow, Stainby, and Nestor, 1958; Cumming and Ferguson, 1962 ; Sabiston, 1963). However, the ideal surgical management of this malformation must be to make continuity between the left coronary artery and the aorta as suggested by Keith (1959) following Mustard's example in 1954. In view of the distance between the transected coronary artery and the ascending aorta, an intermediate graft is necessary. Coo'ey and his associątes (Cooley, Hallman, and Bloodwell, 1966) have had success using a saphenous vein graft in older children, but this is technically difficult and usually unsuccessful in infants. Even if the anastomosis does not remain patent, the beneficial effects that occur following ligation are still to be expected as the left-to-right shunt is abolished and the perfusion pressure in the distal left coronary artery is increased.

In the present case the exercise tolerance, as judged from a controlled effort test with a bicycle ergometer, appears to have improved (Table II). There was no increase in physical activity to produce a training effect in the intervening period to account for the apparent improvement. Improved left ventricular function was suggested by the lessening of the third sound, normal splitting of the second sound and lowering of the resting wedge pressure. The unchanged electrocardiogram in two years does not mean unaltered function, as compensatory left ventricular hypertrophy may not regress, and the area of dead myocardium will not alter. Unfortunately, with the rarity of this lesion it is not possible to compare the results of ligation and anastomosis, and doing nothing, and it is difficult to assess results in asymptomatic people.

Surgery should ideally be delayed until the continuous murmur develops, as this signifies that there is a good retrograde blood flow which must come through the anomalous coronary vessels through the well-developed intercoronary anasto- $\frac{\overline{\bar{O}}}{+}$ motic channels. The variability of the continuous murmur under different physiological conditions 음 shown in this case is presumably due to the differ- $\frac{\bar{c}}{\vec{D}}$ ent coronary blood flow during rest, as compared $\stackrel{\triangleright}{\complement}$ with effort and excitement associated with attend- ® ing the out-patient department. Any patient $\vec{\circ}$ suspected of having this condition because of the obvious left ventricular hypertrophy and $\vec{\omega}$ ischaemia in association with only slight pulmon- $)$ ary plethora should be exercised if no continuous $\overrightarrow{\vec{x}}$ murmur is heard at rest.

The apical murmurs were of interest in this on patient, and were not directly related to the fistu $n$ lous communication, as a late systolic murmur was present after operation, probably due to 오 mitral regurgitation, particularly as a pansystolic murmur was clear after effort. Mitral regurgi- $\bar{z}$ tation may occur as the result of left ventricular dilatation and failure, or from papillary muscle $\stackrel{\supset}{\supset}$ dysfunction from cardiac infarction. Thus, the $\vec{\varphi}$ diagnosis of anomalous coronary artery should be 0 suspected in young patients who present with mitral regurgitation with or without failure from so-called 'fibroelastosis'. In the film taken at age $2 \frac{1}{2}$ years, the left atrium and heart shadow was $\stackrel{0}{0}$ larger, and it is possible that more mitral regurgi- $\mathbb{D}$ tation than was present at age 13 years contributed to this.

Although only long-term follow-up will show the benefit of this operation, we think that left ventricular function has been improved and that the risk of bacterial endocarditis has been eliminated: we hope that these factors will favourably influence survival.

\section{REFERENCES}

Case, R. B., Morrow, A. G., Stainsby, W., and Nestor, J. O. (1958). Anomalous origin of the left coronary artery. The physiologic defect and suggested surgical treatment. Circulation, 17, 1062.

Cooley, D. A., Hallman, G. L., and Bloodwell, R. D. (1966). Definitive surgical treatment of anomalous origin of left coronary artery from pulmonary artery: indications and results. J. thorac. N cardiovasc. Surg., 52, 798.

Cumming, G. R. and Ferguson, C. C. (1962). Anomalous origin of the left coronary artery from the pulmonary artery, func- $N$ tioning as a coronary arteriovenous fistula. Amer. Heart J., 64, 690.

George, J. M., and Knowlan, D. M. (1959). Anomalous origin of the left coronary artery from the pulmonary artery in an adult. New Engl. J. Med., 261, 993.

Kaunitz, P. E. (1947). Origin of left coronary artery from pulmonary artery. Review of the literature and report of two cases. Amer. Heart J., 33, 182.

Keith, J. D. (1959). The anomalous origin of the left coronary artery from the pulmonary artery. Brit. Heart J., 21, 149.

Nora, J. J., McNamara, D. G., Hallman, G. L., Sommerville, R. J., 응 and Cooley, D. A. (1968). Medical and surgical management $\mathbb{D}$ of anomalous origin of the left coronary artery from the pul- $\bigcirc$ monary artery. Pediatrics, 42, 405.

Sabiston, D. C. (1963). Direct surgical management of congenital $\varrho$ and acquired lesions of the coronary circulation. Progr. cardiovasc. Dis., 6, 299. 